\title{
BMJ Open Empathy variation of undergraduate medical students after early clinical contact: a cross-sectional study in China
}

\author{
Xiong Ye, ${ }^{1}$ Haiying Guo, ${ }^{2}$ Zhou Xu, ${ }^{3}$ Hui Xiao (i) ${ }^{2}$
}

To cite: Ye X, Guo H, Xu Z, et al. Empathy variation of undergraduate medical students after early clinical contact: a cross-sectional study in China. BMJ Open 2020;10:e035690. doi:10.1136/ bmjopen-2019-035690

- Prepublication history for this paper is available online. To view these files, please visit the journal online (http://dx.doi org/10.1136/bmjopen-2019035690).

$\mathrm{XY}$ and $\mathrm{HG}$ contributed equally.

Received 12 November 2019 Revised 29 March 2020 Accepted 05 May 2020

Check for updates

(C) Author(s) (or their employer(s)) 2020. Re-use permitted under CC BY-NC. No commercial re-use. See rights and permissions. Published by BMJ.

${ }^{1}$ School of Clinical Medicine, Shanghai University of Medicine \& Health Sciences, Shanghai, China

${ }^{2}$ Department of Respiratory and Critical Care Medicine, Shanghai General Hospital, Shanghai Jiao Tong University, Shanghai, China ${ }^{3}$ Education Department, Shanghai General Hospital, Shanghai Jiao Tong University, Shanghai, China

Correspondence to

Dr Hui Xiao;

xiaohui771210@163.com

\section{ABSTRACT}

Objectives Empathy education is very important for medical students. There is little research on the influence of early clinical practice on the development of empathy and other aspects of professionalism in medical students. The aim of this study was to compare the selfreported empathy levels of first-year and second-year undergraduate medical students before and after their early clinical contact curriculum.

Setting The study was conducted at the Shanghai University of Medicine \& Health Sciences, Shanghai, China. Participants A total of 257 undergraduate medical students participated in the study. The 154 first-year students were studying in 10 community-based teaching hospitals, and the 103 second-year students were studying in 3 university-affiliated hospitals.

Primary and secondary outcome measures Primary measures: the Jefferson Scale of Empathy-Student version (JSE-S) was compared between students of different sexes and in different academic years before their early clinical contact course. Secondary measures: comparisons were made after they finished the curriculum 3 weeks later.

Results A total of 219 of 257 students responded (85.21\% response rate), and 214 answers could be analysed (135 first-year and 79 second-year students; 120 female and 94 male individuals). No significant differences in the empathy scores before early clinical contact were observed between students of different sexes and in different academic years. After early clinical contact, the mean JSE-S score of the participants was significantly higher than the mean score at the beginning of the curriculum.

Conclusions Empathy-focused training during early clinical contact can improve the empathetic capacity of undergraduate medical students. Fostering empathetic attitudes among undergraduate medical students is necessary for the early stage of their medical education. Further research is needed on the long-term effects of empathy-focused education in entry-level medical students.

\section{INTRODUCTION}

Empathy is the ability to understand and share feelings of another ${ }^{1}$ and has cognitive, affective, behavioural and moral dimensions. ${ }^{2}$ The empathetic capacity of healthcare professionals is important to patient' satisfaction

\section{Strengths and limitations of this study}

- We used the Jefferson Scale of Empathy-Student version as a validated instrument, which has good internal consistency (Cronbach's alpha 0.84).

- Empathy was measured using only a single subjective self-reported questionnaire; self-reported scales are influenced by the perception of socially desirable behavior.

- The interval between the two self-reported questionnaires was only 3 weeks, which may have affected the results because of the influence of recent memory.

and compliance, and empathy has been described as a major aspect of professionalism in medicine. ${ }^{3}$ Studies have shown that patients trust empathetic doctors; tend to communicate well with those doctors; provide more detailed information, facilitating diagnosis; and are likely to display improved treatment compliance. ${ }^{56}$ Empathy strengthens interactions between patients and doctors and improves doctors' satisfaction levels. ${ }^{7}$ High levels of empathy in healthcare professionals are connected to positive clinical prognoses for patients, by reducing mental stress, improving self-awareness and reducing anxiety and depression. ${ }^{89}$

For future doctors, education about empathy is as important as enhancing their clinical competence. ${ }^{10} \mathrm{~A}$ systematic review showed that educational interventions can be effective at maintaining and enhancing empathy in undergraduate medical students. ${ }^{11}$ Lim et al introduced a dramabased training method entitled 'How to Act in a Role' to enhance the empathetic communication skills of their medical students. This innovative teaching method increased not only students' self-reported empathy but also their competency with regard to consultation skills. ${ }^{12}$ Other training methods have also been proposed to enhance medical students' comprehension of empathy and 
their empathetic capacity, such as 'communication skills training', ${ }^{13} 14$ 'reflective writing, ${ }^{15} 16$ and 'motivational interviewing training'. ${ }^{17}$ While some studies showed that the empathetic capacity of medical students declined with increasing academic years, ${ }^{18-20}$ others indicated that the empathy scores of students in their final year were higher than those of first-year medical students. ${ }^{21}$ Sex has also been found to influence undergraduate medical students' empathy. ${ }^{22}$ Conflicting results have been found with respect to sex-based differences; a reason for this may be the social-cultural background of the students being investigated..$^{23}$ Moreover, as empathy level is difficult to measure, the standard approach to enhancing empathy in medical students remains debatable. ${ }^{24}$

Early clinical contact (ECC) for medical students is an important curricular innovation and has been found to be particularly crucial for teaching professionalism. ${ }^{25}$ ECC means real-patient contact in a clinical context that enhances the students' understanding of illness and the role of the health professional and that occurs in the early or preclinical years of undergraduate education. ${ }^{26}{ }^{27}$ Some studies showed that contact with patients early in medical students' training elicits a positive emotional response that has the potential to trigger the development of emotional maturity, relational skills and patient-centred attitudes and to promote a better understanding of health and illness. ${ }^{28}{ }^{29}$ However, the impact of ECC on the development of empathy or other professional abilities in medical students remains relatively under-researched..$^{30}$

In this study, we encouraged our first-year and secondyear medical students to focus on empathetic relationships between patients and doctors through our ECC curriculum. We sought to investigate whether ECC altered medical students' empathy and whether there were any differences in this respect in terms of sex and/ or academic year.

\section{METHODS}

\section{Participants}

There were 154 students in the first year and 103 students in the second year who took part in the ECC curriculum at the Shanghai University of Medical \& Health Sciences in China in July 2018. The first-year students were studying in 10 community-based teaching hospitals, and the second-year students were studying in 3 of our university hospitals, with 10-15 students in each group. After informed consent was obtained, 219 medical students completed the measurement of empathy (response rates of $87.66 \%$ of the first-year and $76.70 \%$ of the secondyear students, respectively). In total, 214 returned questionnaires were valid. All of our students are high school graduates, aged between 17 and 21 years. The basic characteristics of all participants are shown in table 1 .

\section{Measurement of empathy}

The Jefferson Scale of Empathy—Student version (JSE-S), created by Hojat and colleagues, ${ }^{31}$ was used in this study. It includes 20 items answered on a 7-point Likert-type scale ( 1 indicating strong disagreement and 7 indicating strong agreement). Ten of the items are positively worded, and 10 are negatively worded. The JSE-S was specifically developed as a self-reporting scale for assessing medical students' attitudes towards empathetic inpatient care. The original JSE-S comprises three components: perspective taking (items 2/4/5/9/10/13/15/16/17/20), compassionate care (items 1/7/8/11/12/14/18/19) and putting yourself in the patient's shoes (items $3 / 6$ ). The total score was obtained by summing all items (total scores range from 20 to 140), with higher scores indicating a higher degree of empathy. JSE-S has received international attention from researchers and has been translated into 56 languages, including Chinese, French, German, Italian and Korean. ${ }^{32} 33$

\section{Procedure}

\section{ECC curriculum}

The ECC curriculum was administered at the end of the school year and was divided into two parts: 1 week of theoretical lectures about empathy and narrative medicine given by a professor and 2 weeks of clinical practice that included empathy-focused training, patient interviews and reflective narrative story writing. We required and guided students to focus on how to care about patients, become patient-centred and make decisions with consideration given to patients and other aspects beyond the clinical diagnosis and treatment of diseases by doctors. In the patient interview, students were required to explore the inner world of patients and the psychological and social changes associated with the illness experienced by

Table 1 Basic characteristics of participants

\begin{tabular}{|c|c|c|c|c|c|c|}
\hline Year & Sex & $\begin{array}{l}\text { All students } \\
\text { N (\%) }\end{array}$ & $\begin{array}{l}\text { Age } \\
\text { M (SD) }\end{array}$ & $\begin{array}{l}\text { Participants } \\
\text { N (\%) }\end{array}$ & Response rates (\%) & Hospital \\
\hline \multirow[t]{2}{*}{ First } & Females & $89(57.80)$ & $18.51(0.77)$ & $78(57.78)$ & 87.66 & \\
\hline & Total & $154(100)$ & $18.38(0.06)$ & $135(100)$ & & \\
\hline \multirow[t]{2}{*}{ Second } & Females & $55(53.40)$ & $18.73(0.13)$ & $42(53.16)$ & 76.70 & \\
\hline & Total & $103(100)$ & $18.85(0.10)$ & $79(100)$ & & \\
\hline
\end{tabular}


the patients and their families. Each student completed interviews independently with at least six patients and wrote two reflective narrative stories during the 2 weeks of clinical exposure. Students shadowed a doctor every day and they were not responsible for the patients' diagnoses and treatments.

\section{Two JSE-S surveys}

An initial JSE-S survey was administered before the lectures in the first week of our ECC curriculum, and the second survey was administered at the end of this curriculum 3 weeks later. The questionnaires were powered by www. wjx.cn and anonymously collected so that students would not feel forced to participate. The platform recorded the time taken to complete the questionnaire, with the average time to complete being $4.2 \mathrm{~min}$. If the completion time of a questionnaire was less than 2 min or more than $10 \mathrm{~min}$, then its result was excluded from the statistical analyses, because completion times on either end of the spectrum affect the quality of the answers. In this study, 5 of 219 returned questionnaires were excluded (2 of them were completed in less than 2 min and 3 in more than $10 \mathrm{~min}$ ).

\section{Data analysis}

Statistical analyses were performed using SPSS V.19.0 software. All values are shown as the means \pm SD. Descriptive analyses were performed for all investigated variables, and a D'Agostino-Pearson $\chi^{2}$ test was used for normally distributed variables. ${ }^{34}$ The Cronbach's alpha was calculated to assess the internal consistency of the questionnaire. Unpaired t-tests were used to compare the differences between two groups, and analysis of variance (two-way analysis of variance) was used for two-factor variance analysis. Statistical significance was defined as $\mathrm{p}<0.05$.

\section{Patient and public involvement}

No patients were involved.

\section{RESULTS}

A total of 219 of the 257 students completed the JSE-S questionnaire (85.21\% response rate), and 214 answers were analysed (135 first-year and 79 second-year students; 120 female and 94 male individuals) for both surveys. The JSE-S scores in our study were approximately normally distributed, and the Cronbach's alpha of the questionnaire was 0.84 . No significant differences were observed between students of different sexes and in different academic years before the ECC curriculum ( $p>0.05$; table 2). After finishing the ECC curriculum, all the students showed a significantly higher mean empathy score as measured by the JSE-S than the score for the whole sample population before the course (table 2). There was a significant difference between students in different grades ( $\mathrm{p}=0.001$; table 3 ), but there was no interaction effect between sex and academic year $(\mathrm{p}=0.759$; table 3).

\section{DISCUSSION}

ECC closes the gap between theory and practice. Hence, many medical schools are adjusting their curricula to provide greater vertical integration between basic and clinical subjects. ${ }^{28}$ Clinical contact can deepen medical students' understanding of professionalism, especially when students face the death of a patient directly ${ }^{35}$; such scenes have a strong impact on the formation of empathy and other professional qualities. ${ }^{36}$ Hojat defined medical empathy as 'a cognitive attribute that mainly includes the understanding of experiences, problems and perspectives of patients, and the ability to communicate this understanding and an intention to help, ${ }^{37}$ Empathy strengthens the relationship between patients and health professionals and improves patient-physician satisfaction. ${ }^{38}$ In some studies, self-reported measures have found that empathy declines during undergraduate medical training. A study by Hojat et al showed that the empathy scores did not change

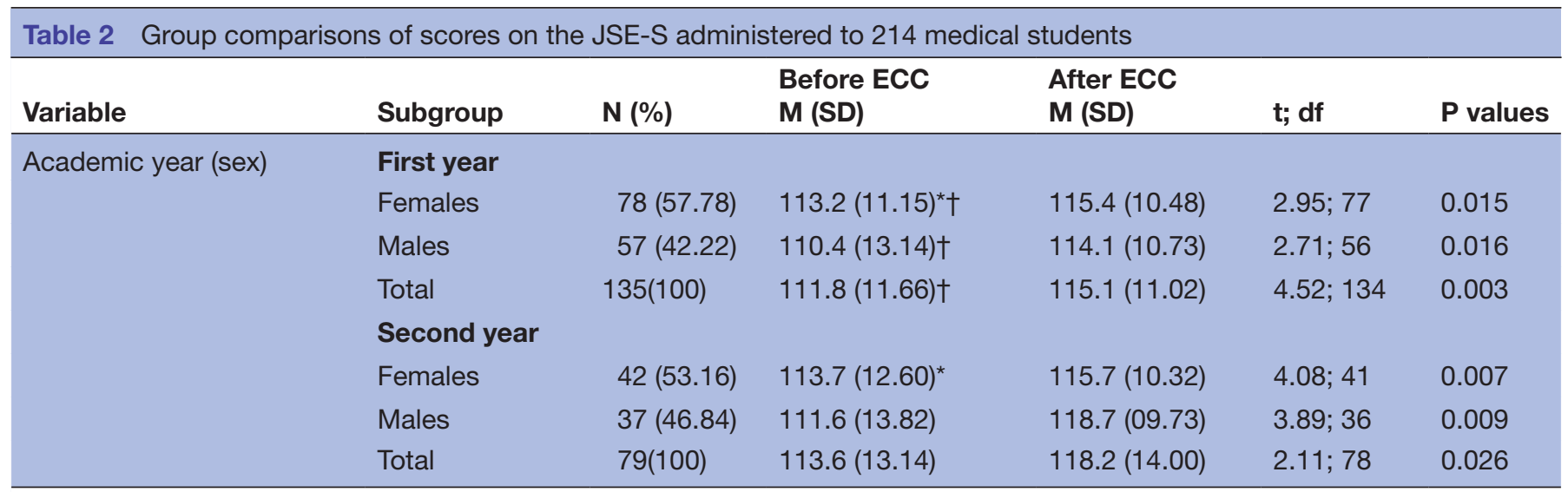

Values are expressed as the mean $(\mathrm{M}) \pm \mathrm{SD}$ or number (\%). $\mathrm{P}>0.05$.

${ }^{*}$ Compared between sexes.

†Compared between different academic years.

ECC, early clinical contact; JSE-S, Jefferson Scale of Empathy-Student version. 
Table 3 Two-way ANOVA of two-factor variance analysis (sex; grade)

\begin{tabular}{llll}
\hline Source of variation & Total variation, $\%$ & $\boldsymbol{F}(\mathbf{d f n}, \mathbf{d f d})$ & $\mathbf{P}$ value \\
\hline Interaction & 0.045 & $F(1,206)=0.095$ & 0.759 \\
Row factor (sex) & 0.598 & $F(1,206)=1.27$ & 0.261 \\
Column factor (grade) & 2.240 & $F(1,206)=4.76$ & 0.001 \\
\hline
\end{tabular}

ANOVA, analysis of variance.

significantly during the first 2 years among their students, but a significant decline was observed at the end of their third year. ${ }^{39}$ However, studies by Eunice and Ulloque $e t$ $a l$ showed that the empathy level of last-year students was higher than that of freshmen. ${ }^{21} 40$

In our study, the Cronbach's alpha was 0.84, which is similar to the findings in some other studies in China ${ }^{414}$ and indicates that the JSPE-S is internally consistent among Chinese medical students. We compared the self-reported empathy levels of two grades of undergraduate medical students before and after the ECC curriculum. The main finding of this study was the improvement in empathy scores in all of our students after ECC. Our ECC curriculum includes not only empathy-focused early clinical exposure to real patients but also theoretical instruction regarding doctor-patient empathy. During ECC, we emphasise the importance of empathy, and students are required to focus on and record real cases of doctor-patient empathy in clinical practice. This suggests that students who attend empathy-focused clinical programmes early in their 5 years of study may establish and strengthen their empathy, which is a key component of medical professionalism. We have unified the requirements for the patient interview and reflective writing for both first-year and second-year students. Reflective narratives are a useful and enjoyable way to teach medical students about issues pertaining to empathy. ${ }^{43}$ Empathy education should be emphasised as a key part of the early integration of patient contact into the curriculum, as it plays an important role in students' future doctor-patient relationships. ${ }^{44}$ Other interesting results were that there were no significant differences between students of different sexes and in different academic years and there was no interaction $(\mathrm{p}=0.759)$ between these two factors. This is not consistent with the findings of some studies that indicated that female students had significantly higher average empathy scores than male students ${ }^{19} 45$ but similar to the results of other studies. ${ }^{32}$ 47-49 The sexbased disparity might be due to 'particular factors' unique to European and American medical students. In some Asian countries, there is often no significant difference, which might be caused by different social-cultural background. ${ }^{48}{ }^{49}$ Our students come directly from high school after passing a unified selective examination. This is essentially different from American medical students, who usually major in different subjects in college. Our university has a course called 'Introduction to Medicine' in the first year, which helps students think about ethics, life and death. The lack of significant differences between different sexes and academic years before ECC in our study may result from different cultures and different sources of students, as addressed earlier. Future research should use multiple forms of measurement to better understand the mechanisms involved in empathy changes in medical students. ${ }^{50}$

One limitation of our study is that empathy was constructed using only a single subjective self-reported questionnaire among undergraduate medical students. Self-reported empathetic capacity is not always accurate and often does not correlate with the patients' assessments ${ }^{5152}$; future research should consider the patients' perspectives as well. Short observation time is the second limitation, and self-reported scales are influenced by the perception of socially desirable behaviour, which means that after the training, students may have become aware of what were the desirable answers on the questionnaire, which may have introduced bias. The main purpose of this study was to observe the short-term impact of ECC on medical students' empathy. The time interval necessary for eliminating bias in the results needs further study, and we will carry out related studies on the long-term effects in our follow-up research.

\section{CONCLUSIONS}

Empathy education is very important for undergraduate medical students to promote the quality of the doctorpatient relationship in their future work. ECC can not only stimulate students' enthusiasm for learning but also play a vital role in the formation of vocational ability. This study revealed that empathy-focused training during ECC could improve the empathetic capacity of our undergraduate medical students. Empathy and other aspects of professionalism should be taught to junior medical students. Further research is needed on the long-term effects of early empathy education in medical students.

Correction notice This article has been corrected since it was published. The affiliation for Haiying Guo \& Hui Xiao has been updated.

Acknowledgements The authors would like to thank our medical students who willingly gave their time to participate in this research. Special thanks to Dave Talbert (an English teacher at Shanghai University of Medicine \& Health Sciences, who comes from Canada) for providing language editing.

Contributors $\mathrm{XY}$ and $\mathrm{HX}$ contributed to design, data analysis and drafting. $\mathrm{HG}$ and ZX contributed to critically revising the paper and agreed to be accountable for all aspects of the work.

Funding This work was supported by a grant from the Education Commission of Shanghai (No: ZZJKYX18011).

Competing interests None declared. 
Patient and public involvement Patients and/or the public were not involved in the design, or conduct, or reporting, or dissemination plans of this research.

\section{Patient consent for publication Obtained.}

Ethics approval Ethics approval was granted by the Human Research Ethics Committee of Shanghai University of Medicine \& Health Sciences, research protocol number 2018/136.

\section{Provenance and peer review Not commissioned; externally peer reviewed.}

Data availability statement Data are available upon reasonable request. All data relevant to the study are included in the article or uploaded as supplementary information. The raw datasets generated and/or analysed during the current study are not publicly available due to privacy concerns but are available from the corresponding author upon reasonable request.

Open access This is an open access article distributed in accordance with the Creative Commons Attribution Non Commercial (CC BY-NC 4.0) license, which permits others to distribute, remix, adapt, build upon this work non-commercially, and license their derivative works on different terms, provided the original work is properly cited, appropriate credit is given, any changes made indicated, and the use is non-commercial. See: http://creativecommons.org/licenses/by-nc/4.0/.

\section{ORCID iD}

Hui Xiao http://orcid.org/0000-0002-1465-4596

\section{REFERENCES}

1 Singer T, Klimecki OM. Empathy and compassion. Curr Biol 2014;24:R875-8.

2 Heyes C. Empathy is not in our genes. Neurosci Biobehav Rev 2018;95:499-507.

3 Kim SS, Kaplowitz S, Johnston MV. The effects of physician empathy on patient satisfaction and compliance. Eval Health Prof 2004:27:237-51.

4 Walsh S, O'Neill A, Hannigan A, et al. Patient-rated physician empathy and patient satisfaction during pain clinic consultations. Ir J Med Sci 2019:188:1379-84.

5 Weilenmann S, Schnyder U, Parkinson B, et al. Emotion transfer, emotion regulation, and Empathy-Related processes in physicianpatient interactions and their association with physician well-being: a theoretical model. Front Psychiatry 2018;9:389-402.

6 Schwenk TL. Physician well-being and the regenerative power of caring. JAMA 2018;319:1543-4.

7 Ditton-Phare P, Loughland C, Duvivier R, et al. Communication skills in the training of psychiatrists: a systematic review of current approaches. Aust N Z J Psychiatry 2017;51:675-92.

8 Lorié Áine, Reinero DA, Phillips M, et al. Culture and nonverbal expressions of empathy in clinical settings: a systematic review. Patient Educ Couns 2017;100:411-24.

9 Hemmerdinger JM, Stoddart SDR, Lilford RJ. A systematic review of tests of empathy in medicine. BMC Med Educ 2007;7:24-32.

10 Han JL, Pappas TN. A review of empathy, its importance, and its teaching in surgical training. J Surg Educ 2018;75:88-94.

11 Batt-Rawden SA, Chisolm MS, Anton B, et al. Teaching empathy to medical students: an updated, systematic review. Acad Med 2013;8:1171-7.

12 Lim BT, Moriarty H, Huthwaite M. "Being-in-role": A teaching innovation to enhance empathic communication skills in medical students. Med Teach 2011;33:e663-9.

13 Winefield HR, Chur-Hansen A. Evaluating the outcome of communication skill teaching for entry-level medical students: does knowledge of empathy increase? Med Educ 2000;34:90-4.

14 Kataoka $\mathrm{H}$, Iwase $\mathrm{T}$, Ogawa $\mathrm{H}$, et al. Can communication skills training improve empathy? A six-year longitudinal study of medical students in Japan. Med Teach 2019;41:195-200.

15 Shapiro J, Rucker L, Boker J, et al. Point-Of-View writing: a method for increasing medical students' empathy, identification and expression of emotion, and insight. Educ Health 2006;19:96-105.

16 Liao $\mathrm{H}-\mathrm{C}$, Wang $\mathrm{Y}-\mathrm{H}$. The application of heterogeneous cluster grouping to reflective writing for medical humanities literature study to enhance students' empathy, critical thinking, and reflective writing. BMC Med Educ 2016;16:234-45.

17 Ekong G, Kavookjian J, Hutchison A. Predisposition for empathy, Intercultural sensitivity, and intentions for using motivational interviewing in first year pharmacy students. Am J Pharm Educ 2017;81:5989-6011.

18 Hojat M, Mangione S, Nasca TJ, et al. An empirical study of decline in empathy in medical school. Med Educ 2004;38:934-41.
19 Chen DCR, Kirshenbaum DS, Yan J, et al. Characterizing changes in student empathy throughout medical school. Med Teach 2012;34:305-11.

20 Neumann M, Edelhäuser F, Tauschel D, et al. Empathy decline and its reasons: a systematic review of studies with medical students and residents. Acad Med 2011;86:996-1009.

21 Magalhães E, Salgueira AP, Costa P, et al. Empathy in senior year and first year medical students: a cross-sectional study. BMC Med Educ 2011;11:52-9.

22 Hojat M, DeSantis J, Shannon SC, et al. The Jefferson scale of empathy: a nationwide study of measurement properties, underlying components, latent variable structure, and national norms in medical students. Adv Health Sci Educ Theory Pract 2018;23:899-920.

23 Huang L, Thai J, Zhong Y, et al. The positive association between empathy and self-esteem in Chinese medical students: a multiinstitutional study. Front Psychol 2019;10:1921-30.

24 Quince T, Thiemann P, Benson J, et al. Undergraduate medical students' empathy: current perspectives. Adv Med Educ Pract 2016;7:443-55.

25 Goldie J, Dowie A, Cotton P, et al. Teaching professionalism in the early years of a medical curriculum: a qualitative study. Med Educ 2007:41:610-7.

26 Dornan T, Bundy C. What can experience add to early medical education? consensus survey. BMJ 2004;329:834-40.

27 Verma M. Early clinical exposure: new paradigm in medical and dental education. Contemp Clin Dent 2016;7:287-8.

28 Wilkinson TJ, Gower S, Sainsbury R. The earlier, the better: the effect of early community contact on the attitudes of medical students to older people. Med Educ 2002;36:540-2.

29 Schei E, Knoop HS, Gismervik MN, et al. Stretching the comfort zone: using early clinical contact to influence professional identity formation in medical students. J Med Educ Curric Dev 2019;6:238212051984387-6.

30 Hayward LM, Black LL, Mostrom E, et al. The first two years of practice: a longitudinal perspective on the learning and professional development of promising novice physical therapists. Phys Ther 2013;93:369-83.

31 Hojat M, Gonnella JS, Nasca TJ, et al. Physician empathy: definition, components, measurement, and relationship to gender and specialty. Am J Psychiatry 2002;159:1563-9.

32 Li D, Xu H, Kang M, et al. Empathy in Chinese eight-year medical program students: differences by school year, educational stage, and future career preference. BMC Med Educ 2018;18:241-50.

33 Cho E, Jeon S. The role of empathy and psychological need satisfaction in pharmacy students' burnout and well-being. BMC Med Educ 2019;19:43-55.

34 Cortina-Borja M. Handbook of parametric and nonparametric statistical procedures, 5th EDN. J R Stat Soc Ser A Stat Soc 2012;175:829-29.

35 Kelly E, Nisker J. Medical students' first clinical experiences of death. Med Educ 2010;44:421-8.

36 Smith-Han K, Martyn H, Barrett A, et al. That's not what you expect to do as a doctor, you know, you don't expect your patients to die." Death as a learning experience for undergraduate medical students. BMC Med Educ 2016;16:108-16.

37 Hojat M. Ten approaches for enhancing empathy in health and human services cultures. J Health Hum Serv Adm 2009;31:412-50.

38 Jani BD, Blane DN, Mercer SW. The role of empathy in therapy and the physician-patient relationship. Forsch Komplementmed 2012;19:252-7

39 Hojat M, Vergare MJ, Maxwell K, et al. The devil is in the third year: a longitudinal study of erosion of empathy in medical school. Acad Med 2009;84:1182-91.

40 Ulloque MJ, Villalba S, Varela de Villalba T, et al. Empathy in medical students of Córdoba, Argentina. Arch Argent Pediatr 2019;117:81-6.

41 Wen D, Ma X, Li H, et al. Empathy in Chinese medical students: psychometric characteristics and differences by gender and year of medical education. BMC Med Educ 2013;13:130-6.

42 Jiang T, Wan X-yun, Liu Y-yuan, et al. [Reliability and Validity of the Jefferson Scale of Physician Empathy in Chinese Medical Students]. Sichuan Da Xue Xue Bao Yi Xue Ban 2015;46:602-5.

43 Dhaliwal U, Singh S, Singh N. Reflective student narratives: honing professionalism and empathy. Indian J Med Ethics 2018;3:9-15.

44 Pohontsch NJ, Stark A, Ehrhardt M, et al. Influences on students' empathy in medical education: an exploratory interview study with medical students in their third and last year. BMC Med Educ 2018;18:231-40.

45 O'Sullivan DM, Moran J, Corcoran P, et al. Medical school selection criteria as predictors of medical student empathy: a cross-sectional study of medical students, Ireland. BMJ Open 2017;7:e016076. 
46 Hojat M, Gonnella JS. Eleven years of data on the Jefferson scale of Empathy-Medical student version (JSE-S): proxy norm data and tentative cutoff scores. Med Princ Pract 2015;24:344-50.

47 Paro HBMS, Daud-Gallotti RM, Tibério IC, et al. Brazilian version of the Jefferson scale of empathy: psychometric properties and factor analysis. BMC Med Educ 2012;12:73-80.

48 Tariq N, Rasheed T, Tavakol M. A quantitative study of empathy in Pakistani medical students: a multicentered approach. J Prim Care Community Health 2017;8:294-9.

49 Rahimi-Madiseh M, Tavakol M, Dennick R, et al. Empathy in Iranian medical students: a preliminary psychometric analysis and differences by gender and year of medical school. Med Teach 2010;32:e471-8.
50 Smith KE, Norman GJ, Decety J. The complexity of empathy during medical school training: evidence for positive changes. Med Educ 2017;51:1146-59.

51 Eva KW, Regehr G. Self-Assessment in the health professions: a reformulation and research agenda. Acad Med 2005;80:S46-54.

52 Bernardo MO, Cecilio-Fernandes D, Lima ARdeA, et al. Investigating the relation between self-assessment and patients' assessments of physicians-in-training empathy: a multicentric, observational, cross-sectional study in three teaching hospitals in Brazil. BMJ Open 2019;9:e029356. 